\title{
Evaluation of Corticosteroid Utilization Pattern in the Various Departments of a Tertiary Care Teaching Hospital, Khammam
}

\author{
${\text { Makbul Hussain Chowdhury }{ }^{1 *}, \text { K. Shravya }}^{1}$, Dr. M. Prasad ${ }^{2}$, Dr. M. Chinna Eswaraiah ${ }^{3}$
}

${ }^{1}$ Pharm. D, Anurag Pharmacy College, Kodad, Suryapet, Telangana-508206, India

${ }^{2}$ Assistant Professor, Anurag Pharmacy College, Kodad, Suryapet, Telangana-508206, India

${ }^{3}$ Principal, Anurag Pharmacy College, Kodad, Suryapet, Telangana-508206, India

\author{
DOI: $10.36348 /$ sjmps.2019.v05i12.012 $\quad$ | Received: 02.12.2019| Accepted: 16.12 .2019 | Published: 30.12 .2019 \\ *Corresponding author: Makbul Hussain Chowdhury
}

\section{Abstract}

Corticosteroids have proved to be extremely effective in the treatment of acute inflammation and chronic inflammatory diseases. Drug utilization review (DUR) is an on-going, systematic, criteria-based program of medicine evaluations that will help ensure appropriate medicine use. The present study aim was to evaluate the drug utilization of Corticosteroids in the various department of a tertiary care teaching hospital, Khammam. A prospective observational study was conducted to evaluate drug utilization pattern of corticosteroids. Total 249 corticosteroids were prescribed Prednisolone was prescribed in $39.5 \%$ prescription followed by hydrocortisone in $27 \%$, budesonide in $19 \%$, methylprednisolone in $15.5 \%$, Dexamethasone in $9.5 \%$, Deltazacort in $7.5 \%$, Prednisone in $4.5 \%$ and Fluhydrocortisone in $2 \%$ respectively. 34 ADRs were detected in the study due to corticosteroid use, facial puffiness was detected in $12.50 \%$, headache in $14.70 \%$, Hypernatremia in $14.70 \%$, Hyperglycemia in $17.64 \%$, hypertension in $26.47 \%$ and osteoporosis in $14.70 \% .72 .6 \%$ of the drugs were prescribed from the NELM list. Clinical pharmacists interact directly with patients in several different ways. Hence, the clinical pharmacist can perform potential role in health care system in assisting physician in altering the number of medications taken, the number of doses taken, improving the patient medication adherence, detect the adverse drug reactions, drug interactions, in patient counselling, improve the health related quality of life and decreasing the health care cost of the patient.

Keywords: Corticosteroid, drug utilization, rational use, adverse drug reaction, drug interaction etc.

Copyright @ 2019: This is an open-access article distributed under the terms of the Creative Commons Attribution license which permits unrestricted use, distribution, and reproduction in any medium for non-commercial use (NonCommercial, or CC-BY-NC) provided the original author and source are credited.

\section{INTRODUCTION}

First isolation of cortisol was done in 1950; corticosteroids have proved to be extremely effective in the treatment of acute inflammation and chronic inflammatory diseases. However, despite their clinical success, oral corticosteroids (OCS) are used sparingly due to a broad array of serious adverse events including bone fractures, osteoporosis, and susceptibility to infections, hyperglycemia, and obesity amongst others [1-3].

Glucocorticoids are widely used as potent antiinflammatory and immunosuppressive drugs to treat a wide range of diseases. However, they are also associated with a number of side effects [3, 4]. Corticosteroids are generally called as "steroids"; they highly improve symptoms and provoke impressive results in different conditions [5]. Due to their powerful anti-inflammatory and immunosuppressive actions, these drugs are being prescribed widely by physicians
$[5,6]$. It is most frequently prescribed for patients with respiratory conditions such as asthma or chronic obstructive pulmonary disease (COPD) [7, 8].

There has been increasing concern regarding the safety of corticosteroids, as a large number of patients are prescribed these drugs for long-term prophylactic treatment $[8,9]$. There are different aspects of concern with regard to systemic side effects like glaucoma, changes in bone mineral density and cataracts, psychiatric effects [10-13].

The World Health Organization has defined Drug Utilization Research (DUR) as "the marketing, distribution, prescription and use of drugs in a society, with special emphasis on the resulting medical, social and economic consequences [14, 15]". Drug utilization evaluation can be used for the description of pattern of drug use, irrational use of drug, to improve the drug quality; the basic objectives drug utilization study is to 
facilitate the rational use of drugs in the community [16].

The goal of a DUE is to assist the optimal medication therapy and ensure that drug therapy meets current standards of treatment. Additional objectives may include:

- Creation of guidelines for appropriate drug utilization.

- Evaluation of the effectiveness of medication therapy.

- Enhancing responsibility in the medicine use process.

- Controlling medicine cost.

- Prevention of medication related problems, for example adverse drug reactions, treatment failures, over-use, under-use, incorrect doses and nonformulary medicine use.

- Identification of areas where further information and education may be needed by healthcare providers [17-19].

\section{AIM AND OBJECTIVES}

Aim

To evaluate the Corticosteroid Utilization Pattern in the Various Departments of A Tertiary Care Teaching Hospital, Khammam.

\section{Objectives}

1. To evaluate the most commonly used corticosteroids in various conditions.

2. To evaluate the dose and frequency of administration of corticosteroid used.

3. To evaluate the most common causes for prescribing corticosteroids.

4. To evaluate the gender distribution pattern of corticosteroids

5. To evaluate the age distribution pattern of corticosteroids.

6. To study the drug interaction induced by corticosteroids.

7. To evaluate the adverse drug reactions induced by corticosteroids.

\section{METHODOLOGY \\ Study Design}

A prospective observational study was conducted to evaluate drug utilization pattern of corticosteroids. Patients prescribed with corticosteroids in various departments, were randomly collected. The drug, dose, dosage, frequency of drugs were noted from the patient's record who prescribed with corticosteroids along with patient's demographics.

\section{Study Site}

The study was carried out in various departments of Mamata General Hospital, Khammam.
Inclusion criteria

- Inpatients prescribed with corticosteroids.

- Patients of both genders.

- Patients above 18 years of age.

Exclusion criteria

- Patients below 18 years of age.

- Lactating and nursing mothers.

- Pregnant women.

- Patients treated on outpatient basis.

- Patients under critical condition and requiring critical care stay.

\section{Sources of Data}

- Inpatient profile form.

- Laboratory data record.

- By conducting patient history interview.

\section{Collection of data}

The data was collected using suitably designed data collection form.

\section{Sample size}

200 patients.

\section{STATISTICAL ANALYSIS}

Statistical analysis was

conducted descriptively by using SPSS 21 software.

\section{Duration of study}

The study was conducted for a period of 6 month after obtaining IEC clearance.

\section{RESULTS}

All subjects satisfy the inclusion and exclusion criteria were included as the study population. Total 200 inpatient subjects prescribed with corticosteroids were included in the study.

\section{Gender categorization}

Subjects were categorized according to gender and out of 200 subjects $94(47 \%)$ were male and 106 $(53 \%)$ were female as shown in table 5.1 and figure 5.1.

Table-1: Gender distribution of the subjects

\begin{tabular}{|l|l|l|}
\hline Gender & No. of subjects & Percentage (\%) \\
\hline Male & 94 & 47 \\
\hline Female & 106 & 53 \\
\hline Total & 200 & 100 \\
\hline
\end{tabular}

\section{STUDY CRITERIA}




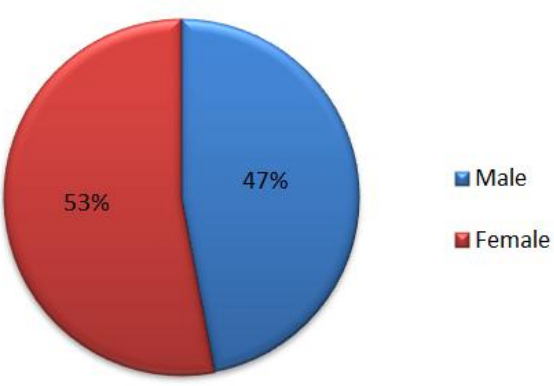

Fig-1: Representing the gender distribution of the subjects

\section{Age group categorization}

Out of 200 subjects $34(17 \%)$ subjects were in age group of $18-30$ years, $42(21 \%)$ subjects were in age group of $31-40$ years, $52(26 \%)$ subjects were in age group of 41-50, 43(21.5\%) subjects were in age group of $51-60,29(14.5 \%)$ subjects were in age group above 60 years shown in table 5.2 and figure 5.5, the mean age of population was $46.66 \pm 15.23($ Mean \pm SD) and the range of ages was between 18->60 years old as shown in table 2 A, 2 B and figure 2.

Table-2 A: Age classification in different categories

\begin{tabular}{|l|c|c|}
\hline Age & No. of subjects & Percentage (\%) \\
\hline $18-30$ & 34 & 17 \\
\hline $31-40$ & 42 & 21 \\
\hline $41-50$ & 52 & 26 \\
\hline $51-60$ & 43 & 21.5 \\
\hline$>60$ & 29 & 14.5 \\
\hline Total & 200 & 100 \\
\hline
\end{tabular}

Table-2: B: Mean age of the population

\begin{tabular}{|c|c|}
\hline Age ranges & Mean age \pm Standard Deviation \\
\hline $18->60$ & $46.66 \pm 15.23$ \\
\hline
\end{tabular}

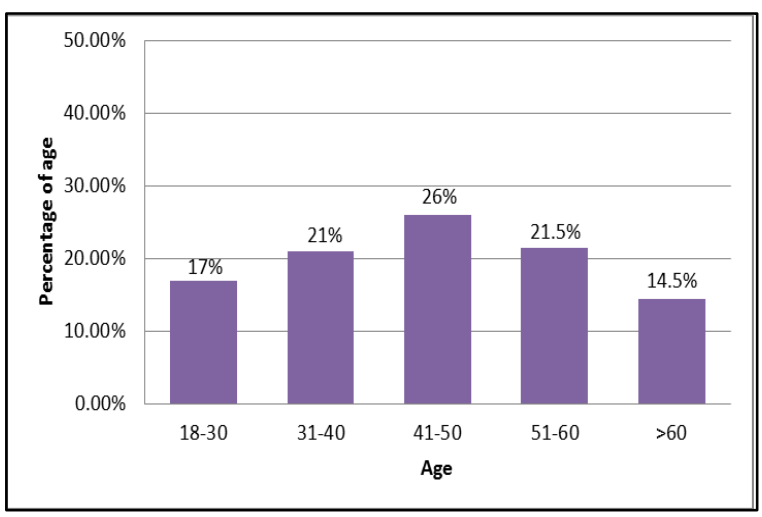

Fig-2: Representing the age group classification

\section{Marital status of subjects}

Out of 200 subjects $172(86 \%)$ were married and $28(14 \%)$ were unmarried as shown in table 3 and figure 3 .
Table-3: Marital status of subjects

\begin{tabular}{|c|c|c|}
\hline Marital status & No. of subjects & Percentage (\%) \\
\hline Married & 172 & 86 \\
\hline Unmarried & 28 & 14 \\
\hline Total & 200 & 100 \\
\hline
\end{tabular}

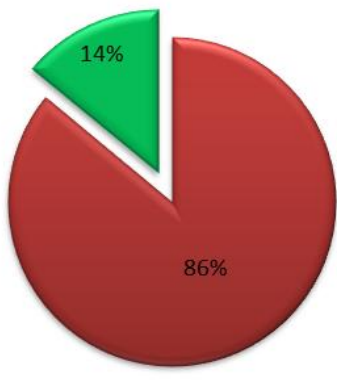

a Married

回Unmarried

Fig-3: Representing the marital status of subjects.

\section{Occupational status}

When distributed according to employment status, out of 200 subjects most of them were in Unorganised sector 94 (47\%), Unemployed 67 (35.5\%), in Organised sector $39(16.67 \%)$ as shown in table 4 and figure 4.

Table-4: Occupational status of subjects

\begin{tabular}{|c|c|c|}
\hline Occupation & Frequency & $\begin{array}{c}\text { Percentage } \\
\text { \% }\end{array}$ \\
\hline Organised & 39 & 19.5 \\
\hline Unorganised & 94 & 47 \\
\hline Unemployed & 67 & 35.5 \\
\hline Total & 200 & 100 \\
\hline
\end{tabular}

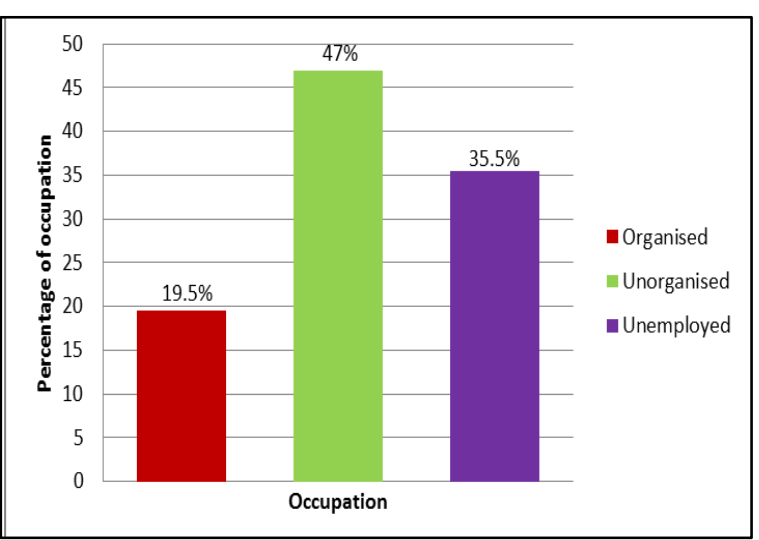

Fig-4: Representing the occupational status of subjects

\section{Frequency of administration}

Out of 249 corticosteroids $107(42.97 \%)$ corticosteroids were prescribed in OD, $95(38.15 \%)$ prescribed in $\mathrm{BD}, 33(13.25 \%)$ prescribed in TDS, 14 (5.62\%) prescribed in QID as shown in table 5 and figure 5 . 
Table 5: Frequency of administration of corticosteroids

\begin{tabular}{|c|c|c|}
\hline $\begin{array}{c}\text { Frequency of } \\
\text { Administration }\end{array}$ & $\begin{array}{c}\text { No. of } \\
\text { prescriptions }\end{array}$ & $\begin{array}{c}\text { Percentage } \\
(\boldsymbol{\%})\end{array}$ \\
\hline OD & 107 & 42.97 \\
\hline BD & 95 & 38.15 \\
\hline TDS & 33 & 13.25 \\
\hline QID & 14 & 5.62 \\
\hline Total & 249 & 100 \\
\hline
\end{tabular}

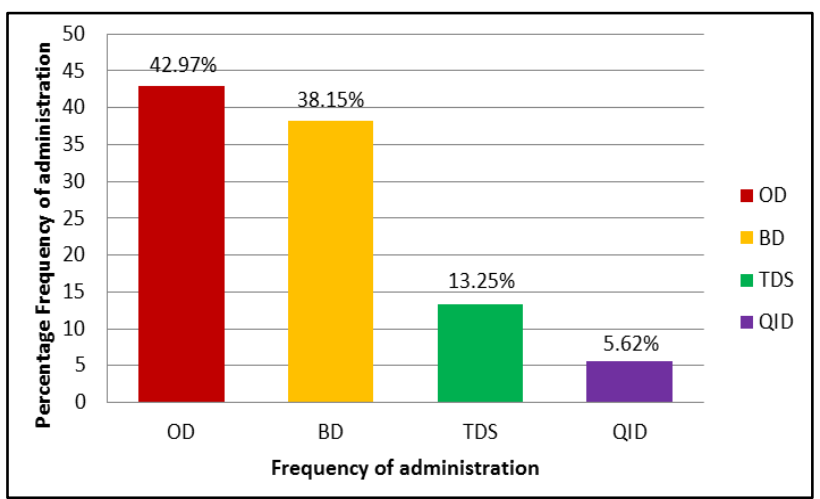

Fig-5: Representing the frequency of corticosteroid administration

\section{Dosage form used in study}

The most preferred route of administration of corticosteroid was oral (37.75\%), Topical (28.92\%), IV $(27.31 \%)$ and inhaler $(6.02 \%)$ respectively as shown in table 6 and figure 6 .

Table-6: Route of Administration of corticosteroids

\begin{tabular}{|l|l|l|}
\hline $\begin{array}{l}\text { Route of } \\
\text { Administration }\end{array}$ & $\begin{array}{l}\text { No. of } \\
\text { drug }\end{array}$ & $\begin{array}{l}\text { Percentage } \\
(\%)\end{array}$ \\
\hline Oral & 94 & 37.75 \\
\hline IV & 68 & 27.31 \\
\hline Inhaler & 15 & 6.02 \\
\hline Topical & 72 & 28.92 \\
\hline Total & 249 & 100 \\
\hline
\end{tabular}

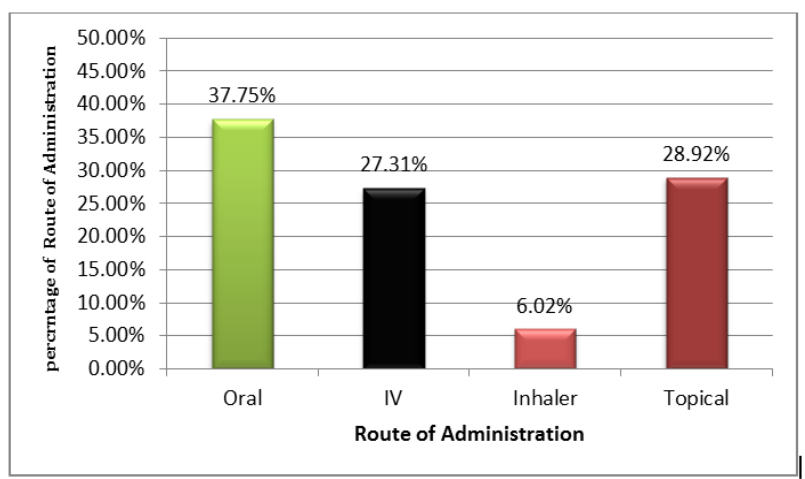

Fig-6: Representing the Route of Administration of corticosteroids

\section{Prescribing pattern of corticosteroids}

Prednisolone was prescribed in $79(39.5 \%)$ prescription followed by hydrocortisone in 54 (27\%), budesonide in 38 (19\%), methylprednisolone in 31 $(15.5 \%)$, Dexamethasone in $19(9.5 \%)$, Deltazacort in 15 (7.5\%), Prednisone in $9(4.5 \%)$ and Fluhydrocortisone in $4(2 \%)$ respectively as shown in table 7 and figure 7 .

Table-7: Corticosteroids used in study

\begin{tabular}{|c|r|l|}
\hline Corticosteroids & Frequency & Percentage (\%) \\
\hline Prednisolone & 79 & 39.5 \\
\hline Hydrocortisone & 54 & 27 \\
\hline Budesonide & 38 & 19 \\
\hline Methylprednisolone & 31 & 15.5 \\
\hline Dexamethasone & 19 & 9.5 \\
\hline Deltazacort & 15 & 7.5 \\
\hline Prednisone & 9 & 4.5 \\
\hline Fluhydrocortisone & 4 & 2 \\
\hline
\end{tabular}

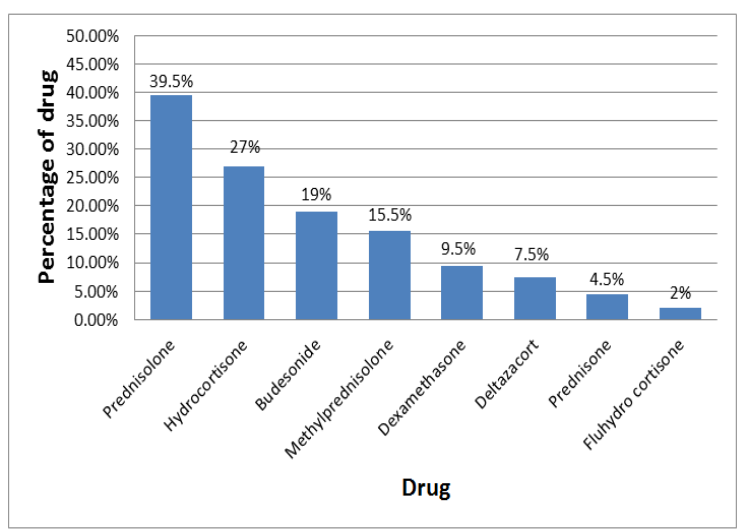

Fig-7: Representing the prescribing pattern of corticosteroids

Distribution of drugs according to generic and branded

$73.09 \%$ (182) drugs were prescribed by branded name and $26.91 \%$ (67) drugs were prescribed in generic name as shown in table 8 and figure 8 .

Table-8: Distribution according to branded and generic name

\begin{tabular}{|c|c|c|}
\hline Drug Type & No. of drugs & Percentage (\%) \\
\hline Branded & 182 & 73.09 \\
\hline Generic & 67 & 26.91 \\
\hline Total & 249 & 100 \\
\hline
\end{tabular}

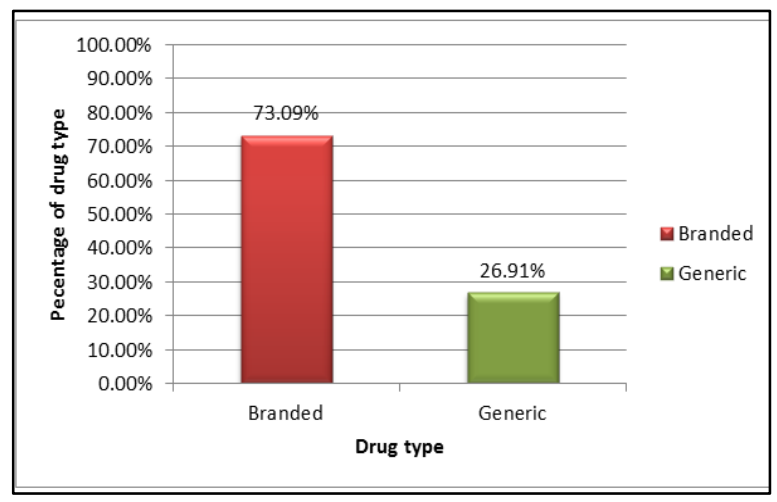

Fig-8: Representing percentage of branded and generic drug 
Distribution of diseases treating with corticosteroids Corticosteroids were used in COPD (11.5\%), Bronchial asthma (8.5\%), RA (10\%), CKD (10\%), Ecezema (5\%), Conjectvitis (2.5\%), Psoriasis $(6.5 \%)$, Cataract (4.5\%), GI (6.5\%), Cellulitis (4.5\%), Glucoma (5.5\%), Occular Sarcodiasis (2\%), Pnemonia (4.5\%), SLE(5.5\%), Occular Oxoplasmois(4\%), Diarrhoea $(1.5 \%)$ and other conditions $(14.5 \%)$ respectively as shown in table 9 and figure 9.

Table-9: Distribution of diseases treated with corticosteroids

\begin{tabular}{|c|c|c|}
\hline Diseases & Frequency & Percentage (\%) \\
\hline COPD & 23 & 11.5 \\
\hline Bronchial asthma & 17 & 8.5 \\
\hline RA & 20 & 10 \\
\hline CKD & 6 & 3 \\
\hline Ecezema & 10 & 5 \\
\hline Conjectvitis & 5 & 2.5 \\
\hline Psoriasis & 13 & 6.5 \\
\hline Cataract & 9 & 4.5 \\
\hline GI & 13 & 6.5 \\
\hline Cellulitis & 9 & 4.5 \\
\hline Glucoma & 11 & 5.5 \\
\hline Occular & & \\
Sarcodiasis & 4 & 2 \\
\hline Pnemonia & 9 & 4.5 \\
\hline SLE & 11 & 5.5 \\
\hline Occular & & \\
\hline Oxoplasmois & 8 & 4 \\
\hline Diarrhoea & 3 & 1.5 \\
\hline Others & 29 & 14.5 \\
\hline
\end{tabular}

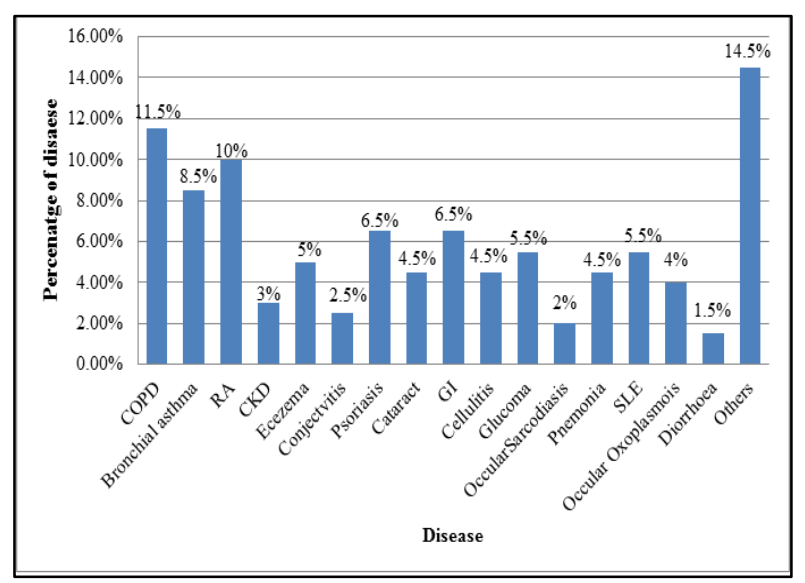

Fig-9: Representing the percentage diseases treated with corticosteroids

\section{ADRs due to corticosteroids}

$34(17 \%)$ ADRs were detected in the study due to corticosteroid use, facial puffiness was detected in $2(12.50 \%)$, headache in $5(14.70 \%)$, Hypernatremia in $5(14.70 \%)$, Hyperglycemia in $6(17.64 \%)$, hypertension in $9(26.47 \%)$ and osteoporosis in 5 $(14.70 \%)$ as shown in table 10 and figure 10 .
Table-10: ADRs due to corticosteroid use

\begin{tabular}{|c|c|c|}
\hline ADRs & Frequency & Percentage (\%) \\
\hline Facial Puffiness & 4 & 11.76 \\
\hline Headache & 5 & 14.70 \\
\hline Hypernatremia & 5 & 14.70 \\
\hline Hyperglycemia & 6 & 17.64 \\
\hline Hypertension & 9 & 26.47 \\
\hline Osteoporosis & 5 & 14.70 \\
\hline
\end{tabular}

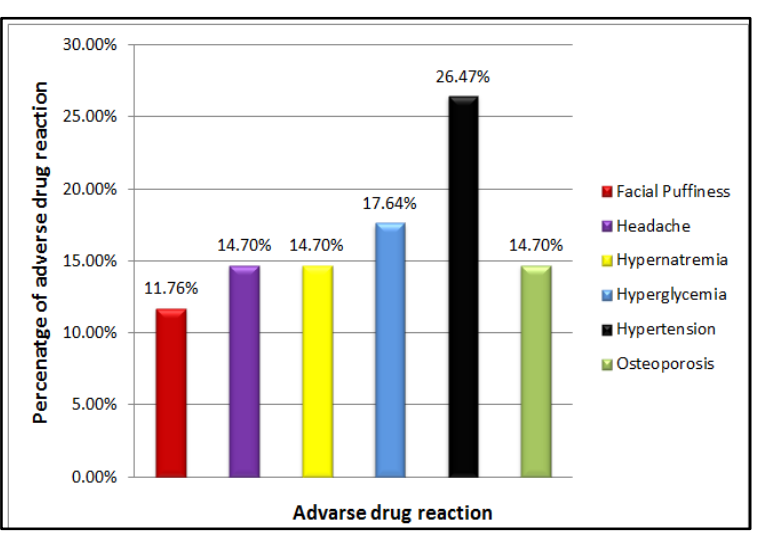

Fig-10: Representing the ADRs due to corticosteroid use.

Causality assessment of ADRs according to Naranjo scale

Out of 34 ADRs 14 (41\%) were probable and $20(59 \%)$ were possible according to Naranjo causality assessment scale as shown in table 11 and figure 11 .

Table-11: Causality assessment of ADRs by Naranjo scale

\begin{tabular}{|c|c|c|}
\hline $\begin{array}{c}\text { Causality Assessment by } \\
\text { Naranjo scale }\end{array}$ & $\begin{array}{c}\text { No. of } \\
\text { ADRs }\end{array}$ & Percentage \% \\
\hline Probable & 14 & 41 \\
\hline Possible & 20 & 59 \\
\hline
\end{tabular}

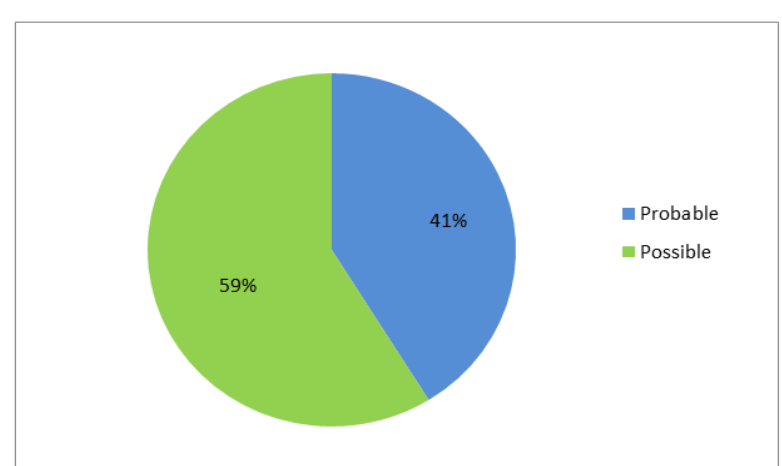

Fig-11: Representing causality assessment of ADRs by Naranjo scale.

Drug interactions with corticosteroids

Total 27 drug interactions were found in 200 prescription, the majority of interactions were moderate $15(55.56 \%)$ followed by minor $7(25.93 \%)$ and major 5 $(18.52 \%)$ respectively as shown in table 12 and figure 12. 
Table-12: Drug interactions with corticosteroids

\begin{tabular}{|c|c|c|}
\hline Interaction & Frequency & Percentage \% \\
\hline Minor & 7 & 25.93 \\
\hline Moderate & 15 & 55.56 \\
\hline Major & 5 & 18.52 \\
\hline
\end{tabular}

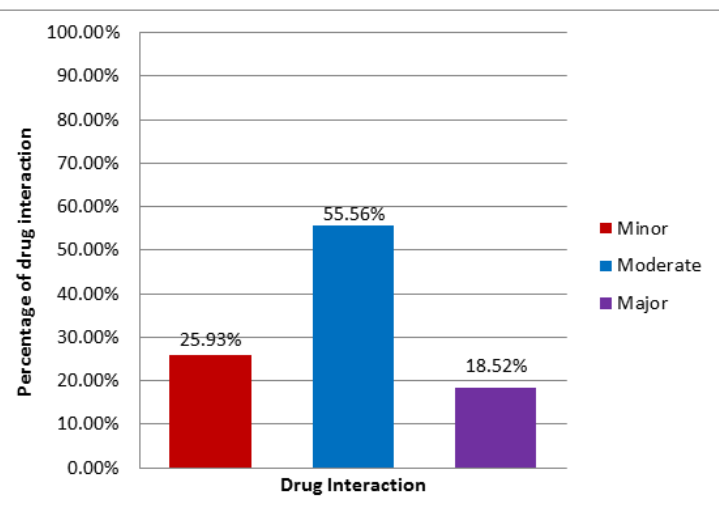

Fig-12: Representing drug interactions with corticosteroids.

\section{Categorization of drugs according to NELM list}

$72.6 \%$ of the drugs were prescribed from the NELM list and $27.4 \%$ drugs are not prescribed from NELM list as shown in table 13 and figure 13.

Table-13: Categorization of drug according to NELM list

\begin{tabular}{|c|c|}
\hline Drugs & Percentage (\%) \\
\hline NELM list & 72.6 \\
\hline Non NELM list & 27.4 \\
\hline
\end{tabular}

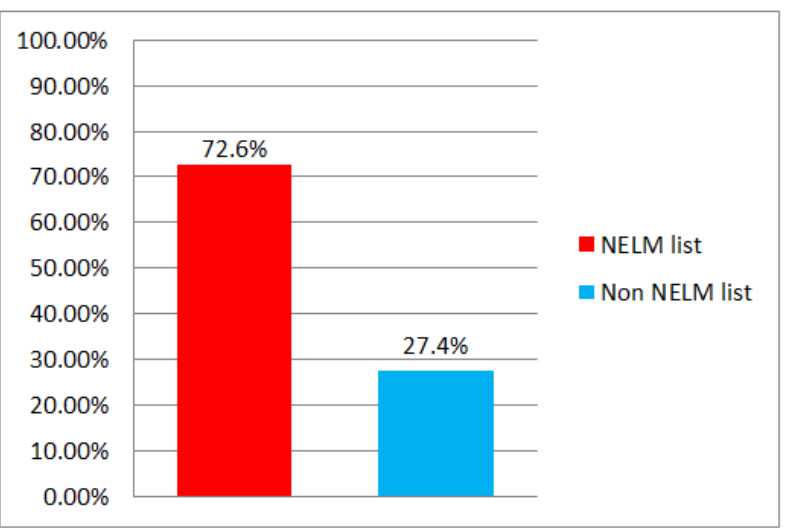

Fig-13: Representing categorization of drug according to NELM list.

\section{Categorization of drugs according to WHO ELM}

$79 \%$ of the drugs were prescribed from the WHO ELM and $21 \%$ drugs are not prescribed from WHO ELM as shown in table 14 and figure 14.

Table-14: Categorization of drug according to WHO ELM

\begin{tabular}{|c|c|}
\hline Drugs & Percentage \% \\
\hline WHO ELM & 78 \\
\hline Non WHO ELM & 22 \\
\hline
\end{tabular}

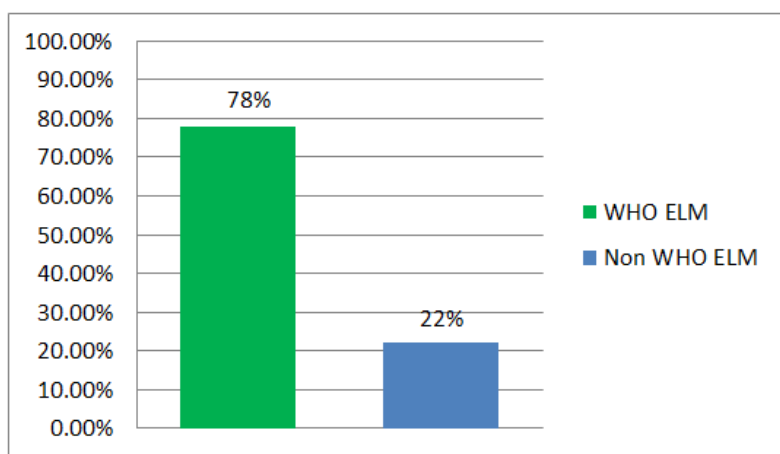

Fig-14: Representing categorization of drug according to WHO ELM

\section{DISCUSSION}

In the present study 200 subjects were included who were prescribed with corticosteroids and admitted to the various inpatient departments of a tertiary care hospital. Demographics details, corticosteroid used, route of administration, dose, dose frequency, dosage form of corticosteroids, condition for use, drug interactions and ADRs subsequent to use of corticosteroids were studied. This study included 200 subjects out of which $106(53 \%)$ were female and 94 $(47 \%)$ were male. The number of married subjects 172 $(86 \%)$ were more than unmarried subjects $28(14 \%)$ There were $66.5 \%$ employed subjects and $33.5 \%$ unemployed subjects in the study. Curtis R Jeffery et al. [19].

Who found that mean age of subjects was $53 \pm 14$ years? The percentage of female $(71 \%)$ was more than male subjects. Percentage of married and employed subjects was $67 \%$ and $56 \%$ respectively. In another study by Laugesen Kristina et al.,[20].

In which the annual prevalence of systemic GC prescription users was higher among women than among men with a prevalence ratio of 1.11 (95\% CI 1.11 to 1.11 ) and prevalence ranging from $3.3 \%$ to $3.7 \%$ in women and $2.7 \%$ to $3.1 \%$ in men.

In the present study age wise distribution, 34 (17\%) subjects prescribed with corticosteroid in age group 18-30 years, $42(21 \%)$ subjects in 31-40 years, 52 $(26 \%)$ in $41-50$ years, $43(21.5 \%)$ in 51-60 years and 29 $(14.5 \%)$ in above 60 years. The mean age of subjects was $46.66 \pm 15.23$. In this the prescribing of corticosteroids were increasing as the age group increased and then decreasing when age crosses 50 years. These factors were comparable with the studies of Overman A. Robert et al. [21] who found that mean age of subjects was 56.5 (54.4-58.7) years. Women (53.3\%; 95\% CI 47.2-59.4) represented a larger proportion of oral glucocorticoid users than men. When stratified by sex, oral glucocorticoid use was reported by $1.3 \%(95 \%$ CI $1.0-1.5)$ of women and $1.2 \%(95 \%$ CI $1.0-1.4$ ) of men. When stratified by sex and age, the prevalence rates were between $0.5 \%$ and $3.5 \%$. Greatest 
use by sex and age was reported in men ages $\geq 80$ years (3.5\%; 95\% CI 2.3-4.7) and women ages 70-79 years $(2.7 \% ; 95 \%$ CI $1.7-3.7)$.

Our finding that prednisolone was the most frequent corticosteroid prescribed $(39.5 \%)$ followed by hydrocortisone $\quad(27 \%)$, budesonide $(19 \%)$, Methylprednisolone (15.5\%), Dexamethasone (9.5\%), deflazacort $(7.5 \%)$, prednisone $(4.5 \%)$ and Fluhydrocortisone (2\%). Out of them $73.09 \%$ (182) drugs were prescribed by branded name and $26.91 \%$ (67) drugs were prescribed in generic name was consistent with the finding of Laugesen $\mathrm{K}$ et al. [20], who reported that $50 \%$ of the total corticosteroid prescription were for prednisolone and Overman R. et al. [21] who reported that prednisolone was the oral corticosteroid most commonly prescribed. In this study it was found that most of the Corticosteroids were prescribed with along with antacid and antibiotics.

In our study out of 249 prescriptions, $42.97 \%$ prescriptions with corticosteroid were prescribed in OD, $38.15 \%$ prescriptions with $\mathrm{BD}, 13.25 \%$ prescriptions with TDS, 5.62\% prescriptions with QID. Among the total no. of prescription Oral route $(37.75 \%)$ is the most preferred route of administration followed by topical $(28.9 \%)$, IV (27.31\%) and inhaler (6.02\%) and which is not consistent to the study of Thakur P.K. et al. [22] in which inhalation $(46.9 \%)$ was the most preferred route of administration followed by injection (37.2\%), oral $(13.4 \%)$, infusion $(0.9 \%)$, topical $(0.9 \%)$, syrup $(0.4 \%)$. This can be due to the difference in the inclusion criteria of the study.

In our study corticosteroids were used in COPD (11.5\%), Bronchial asthma (8.5), RA (10\%), CKD (3\%), Ecezema (2.5\%), Psoriasis (6.5\%), Cataract (4.5\%), GI (6.5\%), Cellulitis (4.5\%), Glucoma (5.5\%), Occular Sarcodiasis (2\%), Pnemonia (4.5\%), SLE (5.5\%), Occular Oxoplasmois (4\%), Diarrhoea (1.5\%) and other conditions (14.5\%) which was consistent to the study by Thakur P.K, et al.[22] in which the major clinical complaints were related to respiratory tract i.e. COPD (20.9\%), LRTI (11.1\%), TB (9.3\%) and pneumonia (7.9\%). COPD was the diagnosis for which most of the corticosteroid was prescribed.

In this study 34 ADRs were found in this study due to corticosteroids use. Facial Puffiness was detected in $4(11.76 \%)$, headache in $5(14.70 \%)$, Hypernatremia in $5(14.70 \%)$, Hyperglycemia in $6(17.64 \%)$, hypertension in $9(26.47 \%)$ and osteoporosis in 5 (14.70\%). By using Naranjo causality assessment scale 14 ADRs were possible and 20 ADRs were probable. Our study was consistent with the study of Treadwell. B. et al. [23] who found that corticosteroid causes hypertension, facial mooning, osteoporosis in the subjects who were on corticosteroid therapy.
In this study out of 200 prescriptions total 27 interactions were found out of which $7(25.93 \%)$ were minor, 15 were $(62.56 \%)$ moderate and $5(18.52 \%)$ were major. Mostly moderate interactions were found in the study which was consistent with the study of Kumar S, et al. [24]. who found that $80 \%$ of the interactions were moderate, $13 \%$ were major and $55.8 \%$ were contraindicated interactions subsequent the use of corticosteroids in his study.

\section{CONCLUSIONS}

Prescription pattern of corticosteroids in this study was not found to be rational (e.g., inadequate dose or polypharmacy) as it may lead to failure of therapy or drug interactions/adverse reactions and increase the cost of therapy/mortality. There was a lack of appropriate guidelines for use of corticosteroids and drug interaction reporting, which could be considered an emerging scope of pharmacy. To ensure safety, efficacy and well balanced therapeutic management with corticosteroids, both patients and prescribers should be more aware of the appropriate dose, dosage regimen, and drug-drug interactions. Periodic monitoring of the drug utilization pattern is one of the methods to analyze the rationality of the drug and has been an effective tool to constitute guidelines for improving the utilization pattern. The clinical pharmacist can perform potential role in health care system in assisting physician in altering the number of medications taken, the number of doses taken, improving the patient medication adherence, preventing the adverse drug reactions, drug-drug interactions, in patient counselling, improves the health related quality of life and decreases the health care cost of the patient.

\section{REFERENCES}

1. Manson, S. C., Brown, R. E., Cerulli, A., \& Vidaurre, C. F. (2009). The cumulative burden of oral corticosteroid side effects and the economic implications of steroid use. Respiratory medicine, 103(7), 975-994.

2. Liu, X. X., Zhu, X. M., Miao, Q., Ye, H. Y., Zhang, Z. Y., \& Li, Y. M. (2014). Hyperglycemia induced by glucocorticoids in nondiabetic patients: a meta-analysis. Annals of nutrition and metabolism, 65(4), 324-332.

3. Shalini, S., Ravichandran, V., Mohanty, B. K., Dhanaraj, S. K., \& Saraswathi, R. (2010). Drug utilization studies-An overview. Inter $J$ Pharmaceut Sci Nanotechnol, 31, 803-10.

4. Bhalla, V., Fong, C. W., Chew, S. K., \& Satku, K. (2006). Changes in the levels of major cardiovascular risk factors in the multi-ethnic population in Singapore after 12 years of a national non-communicable disease intervention programme. Singapore medical journal,47(10), 841.

5. Ankit, P., \& Bharat, G. (2010). Study of drug utilization pattern of glucocorticosteroid drugs with 
special emphasis on their immediate adverse effects in a tertiary care teaching rural hospital. Indian Journal of Pharmacy Practice, 3(4).

6. Schäcke, H., Döcke, W. D., \& Asadullah, K. (2002). Mechanisms involved in the side effects of glucocorticoids. Pharmacology therapeutics, 96(1), 23-43.

7. Shaikh, S., Verma, H., Yadav, N., Jauhari, M., \& Bullangowda, J. (2012). Applications of steroid in clinical practice: a review. ISRN Anesthesiology, 2012.

8. Gupta, P., Bhatia, V. (2008). Corticosteroid physiology and principles of therapy. The Indian Journal of Pediatrics, 75(10):1039-44

9. Holloway, k., Green, T.(2003). Introduction. Drugs and Therapeutic Committees. A Practical Guide. WHO, 1-5.

10. Uboweja, A., Malhotra, S., Pandhi, P. (2006). Effect of inhaled corticosteroids on risk of development of cataract: a meta-analysis. Fundamental and Clinical Pharmacology, 20 (3):305-9

11. Sarnes, E., Crofford, L., Watson, M., Dennis, G., Kan, H., Bass, D. (2011). Incidence and US costs of corticosteroid-associated adverse events: a systematic literature review. Clinical therapeutics, 33(10):1413-32

12. Van Staa, T.P., Leufkens, H.G., Abenhaim, L., Begaud, B., Zhang, B., Cooper, C. (2000). Use of oral corticosteroids in the United Kingdom. Quaterly Journal of Medicine, 93(2):105-11.

13. Uijen, J.H., Van der Wouden, J.C., Schellevis, F.G., Willemsen, S.P., van Suijlekom-Smit L.W., Bindels, P.J.(2011). Asthma prescription patterns for children: can GPs do better?. The European journal of general practice, 17(2):109-15.

14. Kirby, B. (1989). A review of the rational use of corticosteroids. Journal of international medical research, 17(6):493-505

15. World Health Organization.(2003). Introduction to drug utilization research. Oslo: World Health Organization.
16. Management Sciences for Health and World Health Organization. (2007). Drug and Therapeutics Committee Training Course. Submitted to the U.S. Agency for International Development by the Rational Pharmaceutical Management Plus Program. Arlington, VA: Management Sciences for Health,1-3.

17. World Health Organization. (1985). The Rational Use of Drugs. Report of the Conference of Experts. Geneva. World Health Organization.

18. Pradhan, S.C., Shewade, D.G., Shashindran, C.H., Bapna, J.S. (1988). Drug utilization studies. National Med J India, 1(4):185-9.

19. Curtis, J.R., Westfall, A.O., Allison, J., Bijlsma, J.W., Freeman, A., George, V. (2006). Populationbased assessment of adverse events associated with long-term glucocorticoid use. Arthritis Care \& Research, 55 (3):420-6.

20. Laugesen, K., Jørgensen, J.O., Sørensen, H.T., Petersen, I. (2017). Systemic glucocorticoid use in Denmark: a population-based prevalence study. British Medical Journal, 7(5): 1-5.

21. Overman, R.A., Yeh, J.Y., Deal, C.L. (2013). Prevalence of oral glucocorticoid usage in the United States: a general population perspective. Arthritis care \& research, 65(2):294-8.

22. Thakur, P.K., Majid, A., Shramik, M., Kumar, S. (2015). Prospective Study on Drug Utilization Evaluation of Corticosteroids among Out-Patients of Teaching Hospital. InternationalJournal of Pharmacy Teaching \& Practices, 6(4):2630-4.

23. Treadwell, B.L., Sever, E.D., Savage, O., Copeman, W.S.(1964). Side-effects of long-term treatment with corticosteroids and corticotrophin. The Lancet, 283(7343):1121-3.

24. Kumar, S., Thakur, P.K., Shah, S.K.(2017). A prospective assessment of polypharmacy induced drug interactions with corticosteroids. Journal of Chitwan Medical College, 6(1):24-9. 